\title{
Electrodeposition of Crystalline HgTe from a Non-Aqueous Plating Bath
}

\author{
Gabriela P. Kissling, ${ }^{1}{ }^{1,=}$ Mohsin Aziz, ${ }^{2,=}$ Andrew W. Lodge, ${ }^{1}$ Wenjian Zhang, ${ }^{1}$ \\ Mehrdad Alibouri,' Ruomeng Huang, $\oplus^{3}$ Andrew L. Hector, ${ }^{1}{ }^{2}$ Gillian Reid, ${ }^{1}$ \\ Cornelis H. de Groot, $\mathbb{1}^{3}$ Richard Beanland, $\mathbb{1}^{4}$ Philip N. Bartlett, $\mathbb{1}^{1, *, z}$ and David C. Smith ${ }^{2, z}$ \\ ${ }^{I}$ School of Chemistry, University of Southampton, Southampton, SO17 1BJ, United Kingdom \\ ${ }^{2}$ School of Physics and Astronomy, University of Southampton, Southampton, SO17 1BJ, United Kingdom \\ ${ }^{3}$ School of Electronics and Computer Science, University of Southampton, SO17 1BJ, United Kingdom \\ ${ }^{4}$ Department of Physics, University of Warwick, Coventry CV4 7AL, United Kingdom
}

\begin{abstract}
This paper presents a method for the electrodeposition of stoichiometric, crystalline HgTe, which provides advantages over conventional $\mathrm{HgTe}$ preparation techniques, such as physical and chemical vapor deposition, in a number of ways; e.g. fast deposition rates $(2 \mu \mathrm{m} / \mathrm{hr})$ and the ability to reliably produce stoichiometric or near-stoichiometric material. The $\mathrm{HgTe}$ is prepared in a dichloromethane based plating bath using $\left[\mathrm{N}^{\mathrm{n}} \mathrm{Bu}_{4}\right]_{2}\left[\mathrm{TeCl}_{6}\right]$ and $\left[\mathrm{N}^{\mathrm{n}} \mathrm{Bu}_{4}\right]_{2}\left[\mathrm{HgCl}_{4}\right]$ as the precursors for Te and $\mathrm{Hg}$, respectively. The paper details the electrochemical behavior of the plating bath and its components, together with a detailed characterization of the morphology, crystallinity and composition of the prepared HgTe.

(C) The Author(s) 2018. Published by ECS. This is an open access article distributed under the terms of the Creative Commons Attribution 4.0 License (CC BY, http://creativecommons.org/licenses/by/4.0/), which permits unrestricted reuse of the work in any medium, provided the original work is properly cited. [DOI: 10.1149/2.0421816jes]

(cc) BY
\end{abstract}

Manuscript submitted September 19, 2018; revised manuscript received November 16, 2018. Published December 11, 2018.

HgTe is a technologically and scientifically interesting material for a multitude of reasons. In its bulk form it is a semi-metal, which may have applications as a thermoelectric. ${ }^{1}$ In the form of $\mathrm{HgTe} / \mathrm{CdTe}$ quantum well structures the inverted band structure of zinc blende $\mathrm{HgTe}$ leads to a topological phase transition and surface states at the $\mathrm{HgTe} / \mathrm{CdTe}$ interfaces, which demonstrate the quantum spin Hall effect. ${ }^{2}$ In addition, it has recently been shown that it is possible to induce topologically complex superconductivity in the same structures. ${ }^{3}$ Colloidal HgTe quantum dots show very large quantum confinement energies and emission and absorption, which can be diameter-tuned into the telecoms infrared wavelengths and shorter. ${ }^{4}$ This has led to the development of mid-infrared HgTe quantum dot based detectors ${ }^{5}$ and electroluminescent devices. ${ }^{6}$ In addition to being interesting in its own right, $\mathrm{HgTe}$ is also one of the end members of the $\mathrm{HgCdTe}$ system used commercially to produce high-end IR detectors. Interestingly, the production of $\mathrm{HgCdTe}$ alloys by chemical vapor deposition (CVD) is often best achieved by the deposition of alternating $\mathrm{HgTe}$ and CdTe quantum wells which are later interdiffused. ${ }^{7}$

Whilst there are well established techniques for the deposition and patterning of $\mathrm{HgTe}$, there are reasons for believing that electrodeposition of $\mathrm{HgTe}$ may have a real contribution to make. In particular, its additive nature means that electrodeposition is material efficient, which is particularly important considering the toxicity of $\mathrm{Hg}$ and Te. CVD and MBE (molecular beam epitaxy) deposition of HgTe occurs at relatively low temperatures ${ }^{7}$ to limit $\mathrm{Hg}$ loss from the film once deposited, but still allows the deposition of crystalline material. In addition, whilst a number of etching techniques are available for patterning $\mathrm{HgTe}$, its fragility means that etching tends to produce significant doping and other sometimes unwanted effects.

In contrast to the electrodeposition of CdTe which has been widely studied, ${ }^{8,9}$ there is only limited work on the electrodeposition of HgTe. To our knowledge only three groups have published reports on the electrodeposition of HgTe. One example was Stickney and co-workers who prepared HgTe via an electrochemical atomic layer deposition method, by depositing alternate monolayers of $\mathrm{Hg}$ and $\mathrm{Te}$ from aqueous solutions containing one of the precursor species. ${ }^{10}$ The obtained material was near-stoichiometric and crystalline. However, as is characteristic for the electrochemical atomic layer deposition approach, the deposition rates are rather slow (approximately $1 \mathrm{~h} 40$ min per $100 \mathrm{~nm}$ ), which make them less suitable for routine material preparation. Another series of papers discusses the properties of

$=$ These authors contributed equally to this work

*Electrochemical Society Member.

${ }^{z}$ E-mail: d.c.smith@soton.ac.uk; p.n.bartlett@soton.ac.uk galvanostatically prepared $\mathrm{HgTe}$ nanoparticles from aqueous plating baths. ${ }^{11-13}$ They report a change in the nanoparticle composition as a result of changing the electrodeposition current density, but provided little detail on the electrodeposition process. The most thorough discussion of the electrodeposition of HgTe was published by Ortega, ${ }^{14}$ who presented a systematic study on the electrodeposition of $\mathrm{HgCdTe}$ and the related binary compounds onto titanium flags from an aqueous plating bath. They observed the presence of crystalline HgTe in a range of samples deposited from electrolytes containing no cadmium, although in most cases the samples contained excess Te and it is not clear that they were able to deposit "pure" HgTe. The main focus of the Ortega study was the deposition of a range of compositions of $\mathrm{HgCdTe}$. Apart from Ortega's study, further literature exists discussing the electrodeposition of $\mathrm{HgCdTe},{ }^{9,15-17}$ however, none of these studies describe the binary HgTe.

In this paper we will detail the electrodeposition and characterization of HgTe from a non-coordinating solvent based plating bath (i.e. a solvent that has only a very low tendency to bond to the metal ion or to disrupt the coordination environment at the metal center in the precursor complex, for example through substitution of other ligands). The ability to prepare thin films of highly crystalline $\mathrm{HgTe}$ will provide a stepping stone for electrodeposition of $\mathrm{HgTe}$ nanowires and ternary $\mathrm{HgCdTe}$ alloys in the future.

\section{Experimental}

Synthesis.-The synthesis of $\left[\mathrm{N}^{\mathrm{n}} \mathrm{Bu}_{4}\right]_{2}\left[\mathrm{TeCl}_{6}\right]$ was discussed previously. ${ }^{18}\left[\mathrm{~N}^{\mathrm{n}} \mathrm{Bu}_{4}\right]_{2}\left[\mathrm{HgCl}_{4}\right]$ was prepared by a modified method according to Adams et al.:19 To a suspension of $\mathrm{HgCl}_{2}(150 \mathrm{mg}, 0.55$ $\mathrm{mmol})$ in anhydrous dichloromethane $(10 \mathrm{~mL})$ was added $\left[\mathrm{N}^{\mathrm{n}} \mathrm{Bu} 4 \mathrm{Cl}\right.$ (308 $\mathrm{mg}, 1.10 \mathrm{mmol}$ ) with stirring. After one hour, when everything had dissolved, the volatiles were removed in vacuo to give the target compound as a white solid, which can be further purified via recrystallization from dichloromethane solution. Yield: $425 \mathrm{mg}, 93 \%$. Anal. Calcd. for $\mathrm{C}_{32} \mathrm{H}_{72} \mathrm{Cl}_{4} \mathrm{HgN}_{2}$ (827.3): C, $46.45 \% ; \mathrm{H}, 8.77 \%$; N, $3.38 \%$. Found: C, 46.37\%; H, 8.91\%; N, 3.41\%. ${ }^{199} \mathrm{Hg}\left\{{ }^{1} \mathrm{H}\right\}$ NMR spectrum $\left(\mathrm{CD}_{2} \mathrm{Cl}_{2}, 293 \mathrm{~K}\right): \delta=-1139$ (s).

The solubility of both compounds in dichloromethane is relatively high, around $0.4 \mathrm{~g} \mathrm{~mL}^{-1}$. An NMR study providing evidence of the compatibility of the two reagents in $\mathrm{CH}_{2} \mathrm{Cl}_{2}$ solution is provided in the Supplementary Information (see Figures S1 and S2).

Precursor characterization.-Infrared spectra were recorded as Nujol mulls between CsI plates using a Perkin-Elmer Spectrum 
100 spectrometer over the range 4000-200 $\mathrm{cm}^{-1} .{ }^{125} \mathrm{Te}\left\{{ }^{1} \mathrm{H}\right\}$ and ${ }^{119} \mathrm{Hg}\left\{{ }^{1} \mathrm{H}\right\}$ NMR spectra were recorded using a Bruker AV 400 spectrometer and are referenced to external dimethyl tellurium, and $\mathrm{Hg}^{2+}$ in water at $\mathrm{pH}=1$ (then converted to $\mathrm{HgMe}_{2}$ scale), respectively. Microanalyses were undertaken by London Metropolitan University. For all experiments solvents were dried prior to use by distillation over $\mathrm{CaH}_{2}$.

Electrochemical set-up.-The plating bath preparation and the electrochemical measurements were performed in a Belle Technology glove box using a $\mu$ Autolab type III potentiostat. The oxygen and water levels in the glove box were controlled via recirculation of the $\mathrm{N}_{2}$ atmosphere through $\mathrm{O}_{2}$ reducing catalyst and molecular sieve cartridges. $\mathrm{O}_{2}$ levels were kept below $10 \mathrm{ppm}$.

A custom-built small volume electrochemical cell was used to ensure parallel placement of the working and counter electrode. Photographs of the setup are shown in the supplementary information (see Figure S3). $20 \times 10 \mathrm{~mm}$ thin film Pt on Si chips with a $5 \mathrm{~mm}$ diameter exposed area (defined by an O-ring) were used as working electrodes. A $10 \mathrm{~mm}$ diameter Pt : Ir (90\%:10\%) disc was used as the counter electrode and a home-made $\mathrm{Ag} / \mathrm{AgCl}\left(0.1 \mathrm{M}\left[\mathrm{N}^{\mathrm{n}} \mathrm{Bu}_{4}\right] \mathrm{Cl}\right.$ in $\left.\mathrm{CH}_{2} \mathrm{Cl}_{2}\right)$ as the reference electrode.

The plating baths were prepared in $\mathrm{CH}_{2} \mathrm{Cl}_{2}$ from the $\mathrm{Hg}$ and Te precursors using $0.1 \mathrm{~mol} \mathrm{dm}^{-3}\left[\mathrm{~N}^{\mathrm{n}} \mathrm{Bu}_{4}\right] \mathrm{Cl}$ as the supporting electrolyte. The water content is expected to be less than $15 \mathrm{ppm} .{ }^{20}\left[\mathrm{~N}^{\mathrm{n}} \mathrm{Bu} 4\right] \mathrm{Cl}$ (Sigma-Aldrich, $\geq 99.0 \%$ ) was used as-received.

SEM-EDX characterization.-The morphology of HgTe thin films was checked using a Philips XL30 ESEM Scanning Electron Microscope (SEM) at an acceleration voltage of $10 \mathrm{keV}$ with a Secondary Electron (SE) detector. The compositional studies were performed by energy-dispersive X-ray spectroscopy (EDX) using a Thermo Scientific NORAN System 7 X-ray Microanalysis System (operated by NSS spectral software) in spectrum mode at a variety of acceleration voltages. The working distance and X-ray take-off angle from the sample to the detector were $10 \mathrm{~mm}$ and $\sim 35^{\circ}$, respectively. Melt-grown $\mathrm{HgTe}$ (99.999\%) lumps purchased from Alfa-Aesar were used as an EDX standard after grinding and polishing to a mirror finish using colloidal silica.

AFM characterization.-Atomic Force Microscopy (AFM) topography images were collected using a Veeco Multimode V AFM with a silicon tip in tapping mode. The images were collected with a scan rate of $0.3 \mathrm{~Hz}$ and a resolution of 512 lines per scan. The AFM images were analyzed using Gwyddion 2.50 software for the average height and Root Mean Square (RMS) roughness of the HgTe films.

XRD characterization.-X-ray diffraction (XRD) patterns were collected using a Rigaku SmartLab thin film $(9 \mathrm{~kW})$ diffractometer $\left(\mathrm{Cu}-\mathrm{K}_{\alpha}\right)$ in grazing incidence configuration $\left(1^{\circ}\right.$ incident angle $)$ with a parallel incident beam and Hypix-3000 detector. Phase matching and Rietveld refinements used the Rigaku PDXL-2 package and structure models from ICSD. ${ }^{21}$

\section{Results and Discussion}

Electrochemical precursor characterization.-The electrochemical behavior of the individual precursors was investigated in plating baths containing $5 \times 10^{-3} \mathrm{~mol} \mathrm{dm}^{-3}$ of the precursor species and 0.1 $\mathrm{mol} \mathrm{dm}{ }^{-3}\left[\mathrm{~N}^{\mathrm{n}} \mathrm{Bu}_{4}\right] \mathrm{Cl}$ in $\mathrm{CH}_{2} \mathrm{Cl}_{2}$ at Pt thin film $\left(A=0.196 \mathrm{~cm}^{2}\right)$ working electrodes. Cyclic voltammograms recorded in the two plating baths are shown in Figure 1.

On the first scan the reduction of $\left[\mathrm{N}^{\mathrm{n}} \mathrm{Bu}_{4}\right]_{2}\left[\mathrm{HgCl}_{4}\right]$ requires a large nucleation overpotential (see Figure 1a), but on the second and third scans show a clear peak in the voltammetry at $-0.5 \mathrm{~V}$, indicating some surface modification of the platinum caused by the initial deposition of mercury, presumably the formation of a surface alloy. ${ }^{22,23}$ The charge passed in oxidative stripping at around $0.4 \mathrm{~V}$ on the second and third

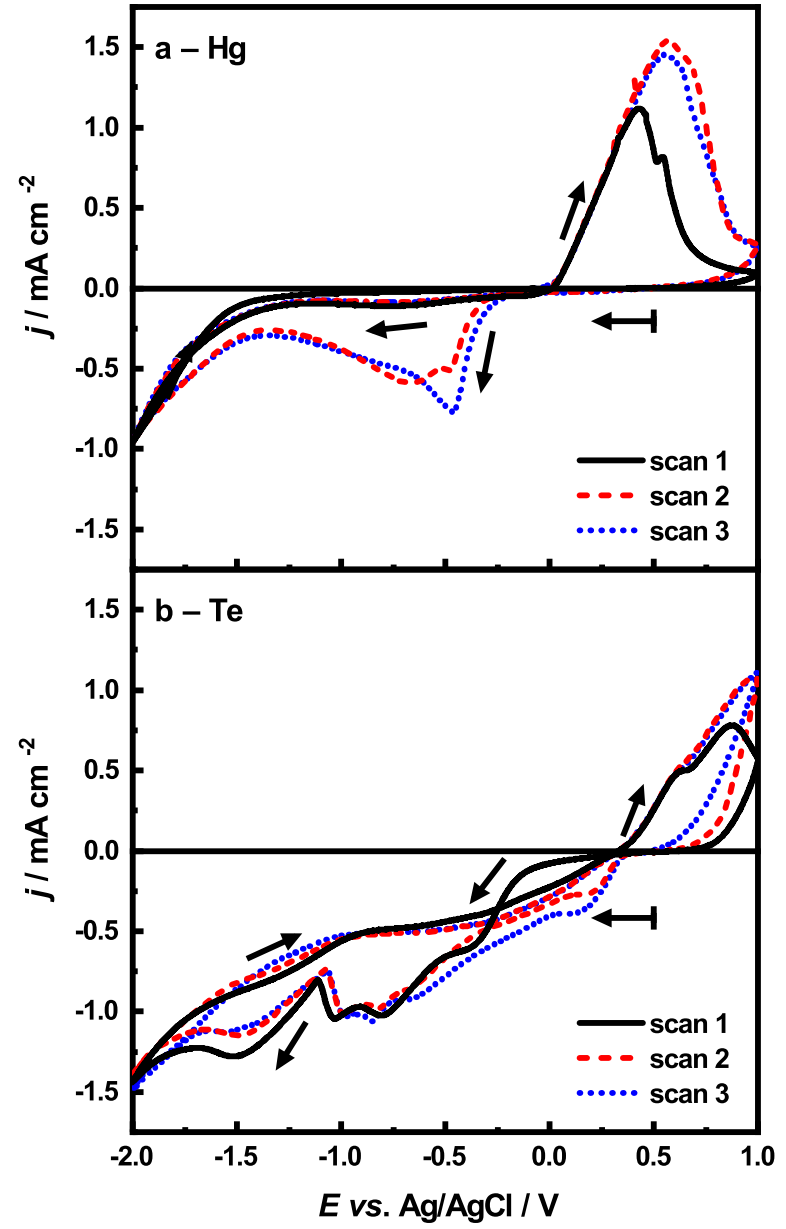

Figure 1. Cyclic voltammograms recorded for the individual precursors in electrolytes containing $5 \times 10^{-3} \mathrm{~mol} \mathrm{dm}{ }^{-3}\left[\mathrm{~N}^{\mathrm{n}} \mathrm{Bu}_{4}\right]_{2}\left[\mathrm{HgCl}_{4}\right]$ (a)

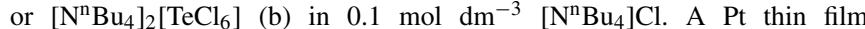
$\left(A=0.196 \mathrm{~cm}^{2}\right)$, a $10 \mathrm{~mm}$ diameter $\mathrm{Pt}: \mathrm{Ir}(90: 10 \%)$ disc and an $\mathrm{Ag} / \mathrm{AgCl}$ $\left(0.1 \mathrm{~mol} \mathrm{dm}^{-3}\left[\mathrm{~N}^{\mathrm{n}} \mathrm{Bu}_{4}\right] \mathrm{Cl}\right)$ were used as the working, counter and reference electrode, respectively. The scan origins at $0.5 \mathrm{~V}$ are indicated by the leftwards arrows with the bar. Further arrows are included to indicate the scan direction.

cycles corresponds to approximately three quarters of the deposition charge.

The electrochemical behavior of tellurium (IV) chloride species in dichloromethane have been discussed by Liftman et al. who studied the voltammetry of $\mathrm{TeCl}_{4}$ in $\mathrm{CH}_{2} \mathrm{Cl}_{2} \cdot{ }^{18,24}$ From Figure $1 \mathrm{~b}$ it is clear that the reduction of $\left[\mathrm{N}^{\mathrm{n}} \mathrm{Bu}_{4}\right]_{2}\left[\mathrm{TeCl}_{6}\right]$ is complex with the first scan again differing from subsequent scans. The main processes occurring in the voltammetry are attributed to the reduction of the Te(IV) complex to $\mathrm{Te}(\mathrm{II})$, the deposition of $\mathrm{Te}(0)$ on the electrode surface, and then at more negative potentials, the reduction of $\mathrm{Te}(0)$ to soluble telluride and/or polytelluride $\left(\mathrm{Te}_{\mathrm{n}}{ }^{2-}\right)$ species: $\mathrm{Te}^{\mathrm{IV}}+2 \mathrm{e}^{-} \rightarrow \mathrm{Te}^{\mathrm{II}}+2 \mathrm{e}^{-} \rightarrow \mathrm{Te}^{0}$ $+2 \mathrm{e}^{-} \rightarrow \mathrm{Te}^{-\mathrm{II}}$. On the first scan the initial reduction wave at around $-0.1 \mathrm{~V}$ is preceded by a slowly rising reduction current which appears to start at $0.5 \mathrm{~V}$. In the cathodic scan reduction peaks are observed at $-0.4 \mathrm{~V},-0.8 \mathrm{~V},-1.0 \mathrm{~V}$, with the marked dip in the voltammetry at $-1.1 \mathrm{~V}$ corresponding to formation of telluride species. This is followed by a further peak at $-1.5 \mathrm{~V}$. In the subsequent scans, the onset of reduction shifts in the anodic direction to $0.3 \mathrm{~V}$, again indicative of some change to the Pt electrode surface. The oxidative stripping onset remains constant at $0.3 \mathrm{~V}$ for all scans, but the stripping currents increase compared to the initial scan. In all cases the stripping charges only account for approximately $10 \%$ of the deposition charges. This can be attributed to the loss of deposited Te during the formation $\mathrm{Te}^{-\mathrm{II}}$, as well as to the formation of soluble $\mathrm{Te}^{\mathrm{II}}$ species. It should be noted 


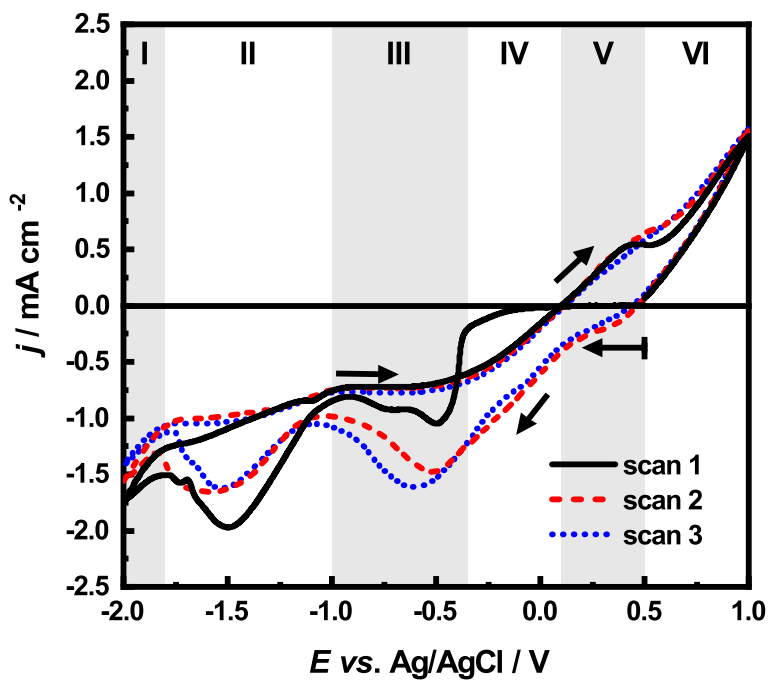

Figure 2. Cyclic voltammograms recorded in an equimolar $\mathrm{HgTe}$ plating bath containing $5 \times 10^{-3} \mathrm{~mol} \mathrm{dm}{ }^{-3}$ each of $\left[\mathrm{N}^{\mathrm{n}} \mathrm{Bu}_{4}\right]_{2}\left[\mathrm{HgCl}_{4}\right]$ and $\left[\mathrm{N}^{\mathrm{n}} \mathrm{Bu}_{4}\right]_{2}\left[\mathrm{TeCl}_{6}\right]$ in $0.1 \mathrm{~mol} \mathrm{dm}{ }^{-3}\left[\mathrm{~N}^{\mathrm{n}} \mathrm{Bu} 4\right] \mathrm{Cl}$. A Pt thin film $(\mathrm{A}=0.196$ $\left.\mathrm{cm}^{2}\right)$, a $10 \mathrm{~mm}$ diameter Pt : $\mathrm{Ir}(90: 10 \%)$ disc and an $\mathrm{Ag} / \mathrm{AgCl}\left(0.1 \mathrm{~mol} \mathrm{dm}^{-3}\right.$ $\left[\mathrm{N}^{\mathrm{n}} \mathrm{Bu}_{4}\right] \mathrm{Cl}$ ) were used as the working, counter and reference electrode, respectively. The scan origin at $0.5 \mathrm{~V}$ is indicated by the leftwards arrow with the bar. Further arrows are included to indicate the scan direction. Note the significant anodic shift of the nucleation onset after the first scan. The highlighted boxes (I - VI) indicate different regions of the voltammograms.

that a visible tellurium deposit remains on the electrode surface after the voltammetry, indicating incomplete stripping.

Combining the two precursors in a single equimolar plating bath gives the voltammetric response shown in Figure 2 which shows some features reminiscent of the Te plating solution but with clear differences. Again the first scan at the fresh Pt electrode is different from the subsequent scans.

The onset of reduction on the first scan occurs at $0 \mathrm{~V}$ and at first increases slowly before increasing more rapidly to a peak at around $-0.5 \mathrm{~V}$; this is reminiscent of the behavior of the Te deposition on the first scan. There is then a second peak at $-1.5 \mathrm{~V}$ and beyond that at around $-1.8 \mathrm{~V}$ a small dip in the current; again this is reminiscent of the more pronounced dip seen in the Te voltammetry and attributed to formation of telluride and/or polytelluride. On the reverse scan there is a plateau in the current between -1.0 and $-0.3 \mathrm{~V}$ and then at anodic potentials a stripping peak is observed at $0.45 \mathrm{~V}$ and an increasing oxidation current beyond $0.5 \mathrm{~V}$. presumably associated with further stripping and chlorine generation from the electrolyte. The voltammetry on the second and subsequent cycles at positive potentials is indicative of the fact that $\mathrm{HgTe}$ can react with $\left[\mathrm{TeCl}_{6}\right]^{2-}$ to oxidize the $\mathrm{Hg}$ and deposit $\mathrm{Te}$ by galvanic displacement as shown by the shift in the onset potential for reduction to $0.25 \mathrm{~V}$. Note that the reduction peak at $-1.5 \mathrm{~V}$ in the $\mathrm{HgTe}$ voltammetry is not due to residual water in the solution, since it does not change upon deliberate addition of water to the plating bath.

Some variations in the voltammetry were seen between experiments, even when the same conditions were used (see Figure S4 in the Supplementary Information). We attribute these variations mostly to differences in the initial thin film Pt electrodes since they were more significant on the first scans than on the subsequent scans. They did not affect the properties of the deposits.

In Figure 2 we have highlighted the different regions in the voltammetry: (I) electrolyte breakdown; (II and III) the two cathodic plateau regions; (IV) the current onset region; and (V and VI) the two stripping regions, where in region $(\mathrm{V})$ we observe a reduction current in the cathodic scan direction attributed to the reduction of Te(IV).

HgTe deposits were prepared in all regions where reduction currents were observed (regions I - V), but especially in regions (II) and

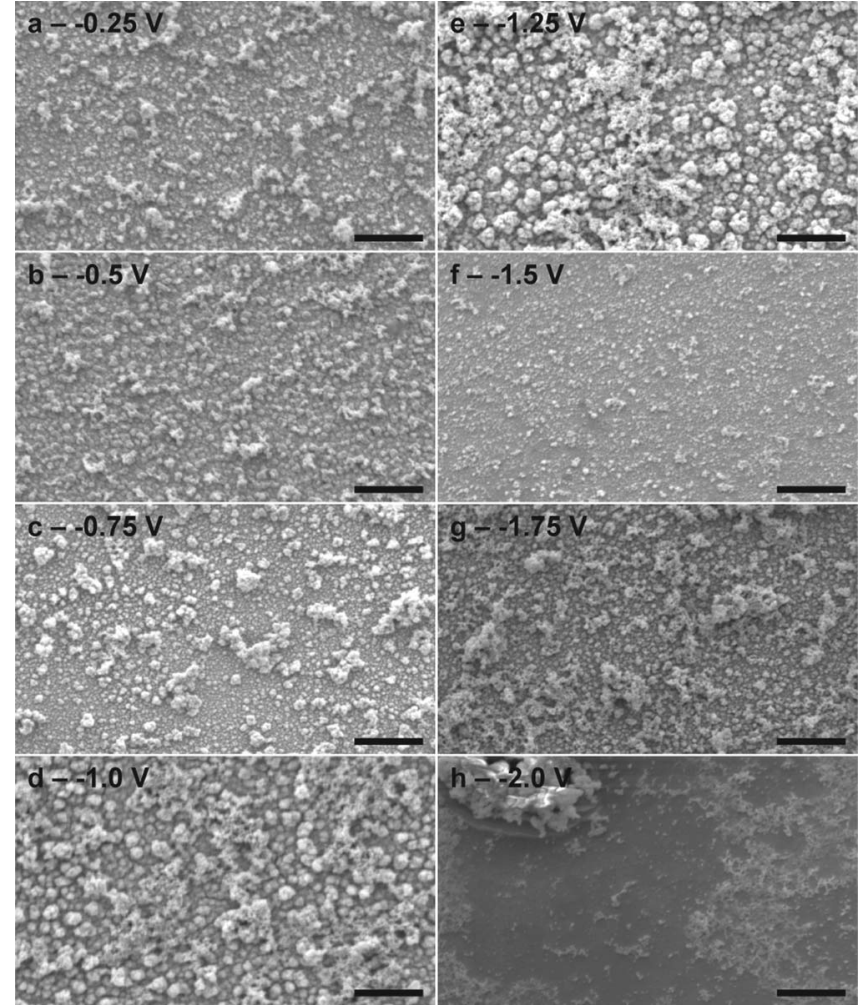

Figure 3. SEM SE images of the surface morphology of HgTe thin films on Pt coated Silicon substrates electrodeposited from a plating bath containing $5 \times 10^{-3} \mathrm{~mol} \mathrm{dm}-3$ each of $\left[\mathrm{N}^{\mathrm{n}} \mathrm{Bu}_{4}\right]_{2}\left[\mathrm{HgCl}_{4}\right]$ and $\left[\mathrm{N}^{\mathrm{n}} \mathrm{Bu}_{4}\right]_{2}\left[\mathrm{TeCl}_{6}\right]$ in $0.1 \mathrm{~mol} \mathrm{dm}^{-3}\left[\mathrm{~N}^{\mathrm{n}} \mathrm{Bu}_{4}\right] \mathrm{Cl}$ in $\mathrm{CH}_{2} \mathrm{Cl}_{2}$. The deposition potentials are provided in the figure panels. The scale bars represent $10 \mu \mathrm{m}$.

(III). The deposits were prepared at a constant deposition potential. The thickness of the deposits was either controlled by the deposition time or by interrupting the deposition once a certain charge was passed. Most deposits discussed in this paper have a nominal thickness of $556 \mathrm{~nm}$ which was achieved by interrupting the deposition once a charge of $-0.8 \mathrm{C} \mathrm{cm}^{-2}$ was reached.

Morphological characterization.-The surface morphology of the deposited $\mathrm{HgTe}$ films was routinely checked by imaging with Scanning Electron Microscopy. Representative SE SEM images of a series of films deposited at a range of potentials from $-0.25 \mathrm{~V}$ to $-2.0 \mathrm{~V}$ from an electrolyte containing $5 \times 10^{-3} \mathrm{~mol} \mathrm{dm}^{-3}$ each of $\left[\mathrm{N}^{\mathrm{n}} \mathrm{Bu}_{4}\right]_{2}\left[\mathrm{HgCl}_{4}\right]$ and $\left[\mathrm{N}^{\mathrm{n}} \mathrm{Bu}_{4}\right]_{2}\left[\mathrm{TeCl}_{6}\right]$ in $0.1 \mathrm{~mol} \mathrm{dm}{ }^{-3}\left[\mathrm{~N}^{\mathrm{n}} \mathrm{Bu}_{4}\right] \mathrm{Cl}$ in $\mathrm{CH}_{2} \mathrm{Cl}_{2}$ are presented in Figure 3. In each case the deposition was terminated after a charge of $-0.8 \mathrm{C} \mathrm{cm}^{-2}$ was passed. SEM and optical images of the full deposition area are presented in the Supplementary Information (see Figures S5 and S6). The SEM images show that after electrodeposition all the films were covered with a deposit which, as will be shown later, was predominantly $\mathrm{HgTe}$. This forms as a mostly continuous, reasonably smooth layer with particulates on top. The only obvious significant difference in the morphology of the films deposited at different potentials is that at more negative potentials, e.g. more cathodic than $-1.5 \mathrm{~V}$, there is evidence of delamination after deposition.

AFM topography measurements were performed on a selection of the films presented in Figures 3 (those deposited at $-0.5 \mathrm{~V}$, $-1.0 \mathrm{~V}$ and $-1.25 \mathrm{~V}$ - Figures $3 \mathrm{~b}, 3 \mathrm{~d}$ and $3 \mathrm{e}$ ) to determine the thickness and roughness of the deposits. The HgTe films were mechanically scratched prior to the measurements using a wooden tooth pick to reveal the Pt layer (see Figure S7 in the Supplementary Information). The revealed surface was Pt colored when observed under an optical microscope and AFM measurements showed it to be flat (apart from some residual deposit) and with no evidence of scratches. 


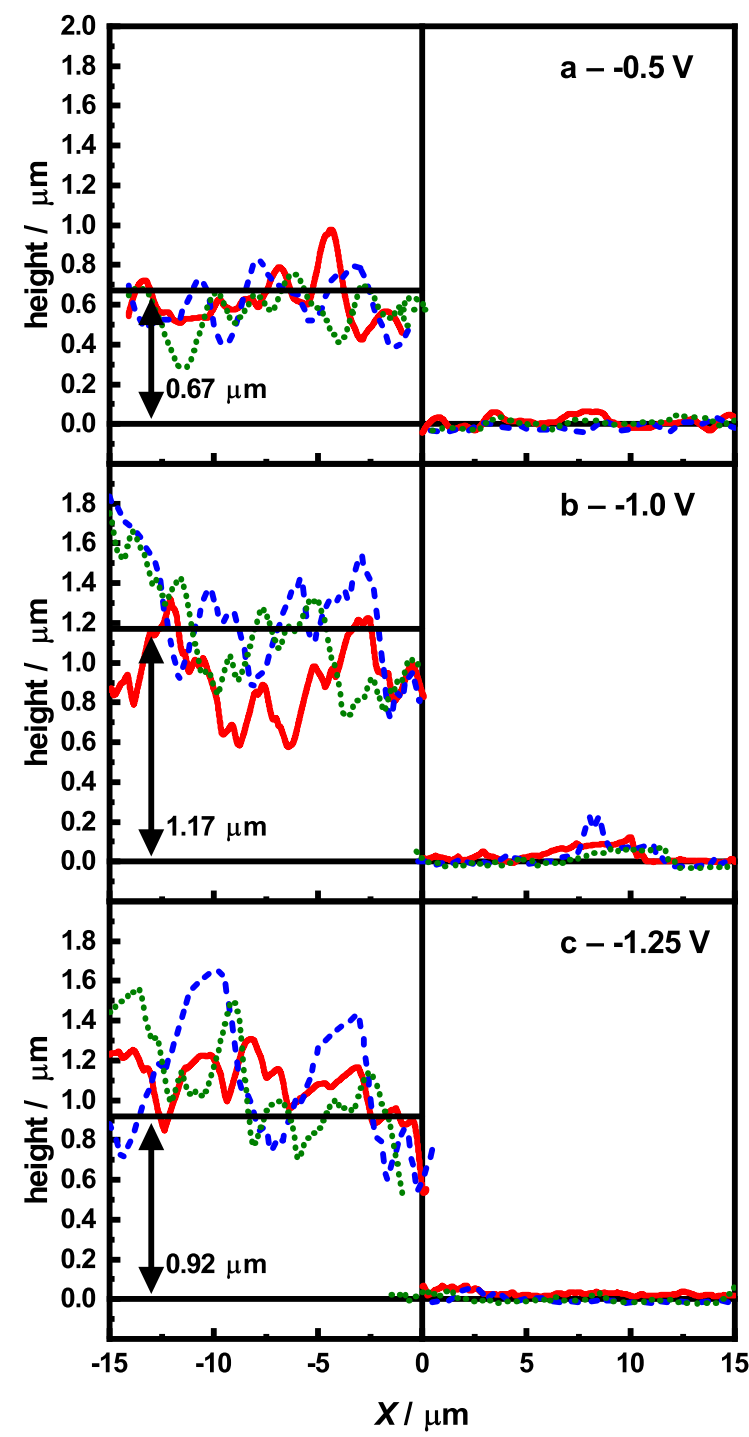

Figure 4. AFM height profiles for films deposited at $-0.5 \mathrm{~V}$ (a), $-1.0 \mathrm{~V}$ (b) and $-1.25 \mathrm{~V}$ (c) across the edge of a scratch which reveals the Pt surface. These are presented with the Pt surface on the right and the $X$ origin adjusted to the edge of the scratch. The features at $X=5-10 \mu \mathrm{m}$ on the $-1 \mathrm{~V}$ profiles are associated with residual film not entirely removed by the scratching process. The average thicknesses reported in the main text are indicated on each plot.

AFM area scans were performed at three locations along the edge of the scratch; two areas approximately $1 \mathrm{~mm}$ in from the edge of the deposit and one area near the center of the deposit. In general the results from the three areas were in good agreement. However, it was observed in other measurements that the very edge of the deposit was significantly $(\sim 30 \%)$ thicker. Representative line scans from the topography measurements taken in the middle of the three samples are shown in Figure 4 and additional results are presented in the Supplementary Information (see Figure S7). The thickness of the deposits was determined by fitting five line profiles in each area and averaging the 15 results. The thicknesses obtained were $0.67 \pm 0.12 \mu \mathrm{m}$, $1.17 \pm 0.07 \mu \mathrm{m}$, and $0.92 \pm 0.33 \mu \mathrm{m}$, for the samples deposited at $-0.5 \mathrm{~V},-1.0 \mathrm{~V}$ and $-1.25 \mathrm{~V}$, respectively. The errors quoted are the standard deviation of the 15 results. The RMS roughness of the deposits was separately determined from a $5 \mu \mathrm{m}^{2}$ area on the three central measurements after plane fitting. The roughness so obtained was $135.4 \pm 18.5 \mathrm{~nm}, 260.8 \pm 17.6 \mathrm{~nm}$, and $311.9 \pm 10.6 \mathrm{~nm}$ for the samples deposited at $-0.5 \mathrm{~V},-1.0 \mathrm{~V}$ and $-1.25 \mathrm{~V}$, respectively. The obtained deposit thicknesses are somewhat greater than the nomi-
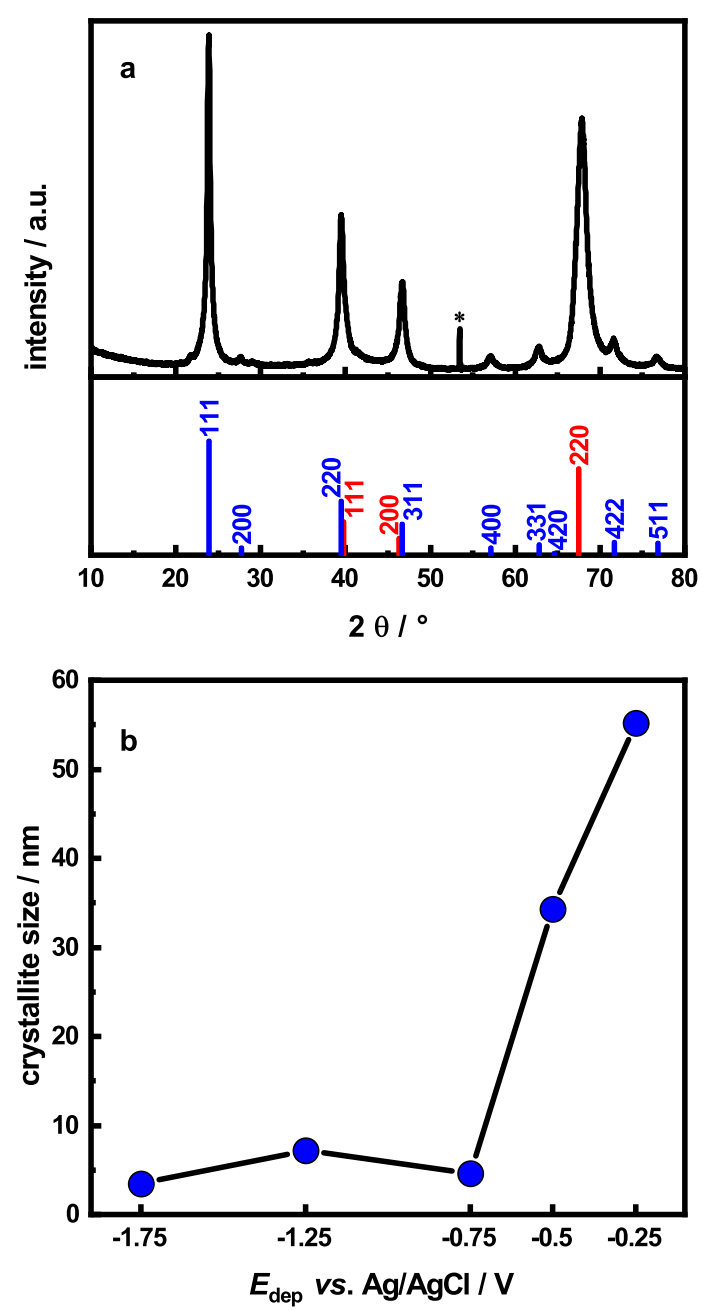

Figure 5. a - XRD pattern of $\mathrm{HgTe}$ on Pt coated Si substrate electrodeposited from a plating bath containing $5 \times 10^{-3} \mathrm{~mol} \mathrm{dm}^{-3}$ each of $\left[\mathrm{N}^{\mathrm{n}} \mathrm{Bu}_{4}\right]_{2}\left[\mathrm{HgCl}_{4}\right]$ and $\left[\mathrm{N}^{\mathrm{n}} \mathrm{Bu}_{4}\right]_{2}\left[\mathrm{TeCl}_{6}\right]$ in $0.1 \mathrm{~mol} \mathrm{dm}^{-3}\left[\mathrm{~N}^{\mathrm{n}} \mathrm{Bu}_{4}\right] \mathrm{Cl}$ in $\mathrm{CH}_{2} \mathrm{Cl}_{2}$ at a deposition potential of $-0.5 \mathrm{~V}$. The expected XRD diffraction peaks of HgTe (blue) and Pt (red) taken from the ICSD database are also shown at the bottom. The starred peak is a forbidden silicon 311 reflection from the substrate. $b$ - "crystallite size" extracted from the XRD patterns by the Halder-Wagner method for a series of samples electrodeposited at potentials between $-0.25 \mathrm{~V}$ and $-1.75 \mathrm{~V}$.

nal $556 \mathrm{~nm}$ thickness calculated using $100 \%$ faradaic efficiency, a 6-electron deposition reaction and the density of single crystal $\mathrm{HgTe}$ $\left(\rho=8.1 \mathrm{~g} \mathrm{~cm}^{-3}\right){ }^{7}$ This is not unexpected due to the polycrystalline nature of the film, which leads to a lower average density of the film relative to the density of the single crystal material.

Crystallographic characterization of the HgTe deposits.Grazing incidence XRD patterns were collected on 10 samples obtained from a variety of plating bath compositions and deposition potentials. A representative XRD pattern for a sample deposited from a plating bath containing $5 \times 10^{-3} \mathrm{~mol} \mathrm{dm}^{-3}$ each of $\left[\mathrm{N}^{\mathrm{n}} \mathrm{Bu}_{4}\right]_{2}\left[\mathrm{HgCl}_{4}\right]$ and $\left[\mathrm{N}^{\mathrm{n}} \mathrm{Bu}_{4}\right]_{2}\left[\mathrm{TeCl}_{6}\right]$ in $0.1 \mathrm{~mol} \mathrm{dm}{ }^{-3}\left[\mathrm{~N}^{\mathrm{n}} \mathrm{Bu}_{4}\right] \mathrm{Cl}$ in $\mathrm{CH}_{2} \mathrm{Cl}_{2}$ at a deposition potential of $-0.5 \mathrm{~V}$ is shown in Figure 5a. Further diffraction patterns for a series of samples deposited at different potentials are shown in the Supplementary Information (Figure S8). All of the features observed in the XRD patterns can be explained in terms of cubic (zinc blende-type) polycrystalline $\mathrm{HgTe}, \mathrm{Pt}$ or the Si substrate. ${ }^{21} \mathrm{In}$ particular, there is no evidence of crystalline Te peaks. ${ }^{21}$ There is also no evidence of preferred crystal orientation of the HgTe. As shown in Figure S8, there is clear evidence of a change in the width of the HgTe diffraction peaks with the deposition potential. Therefore, we 


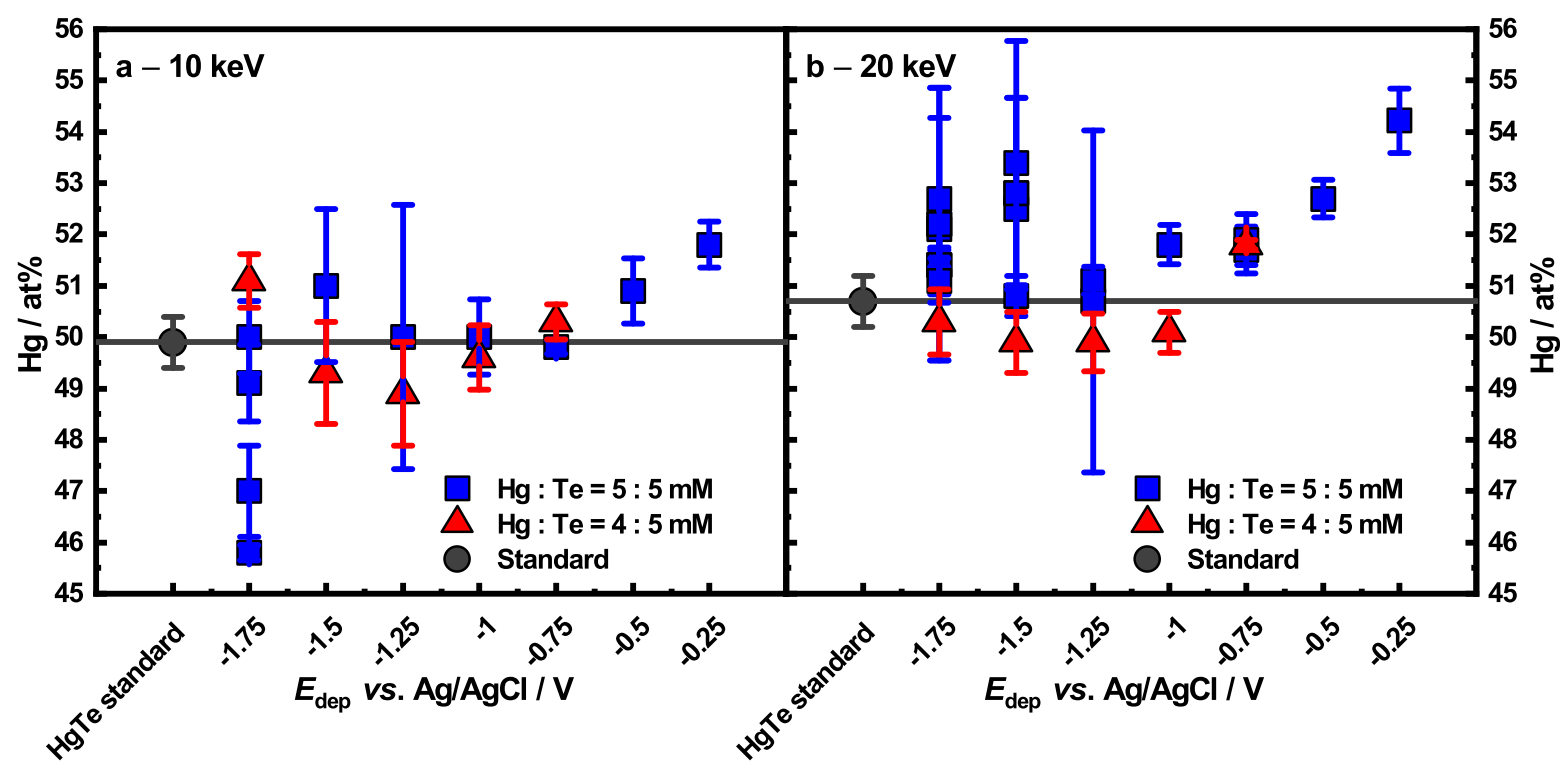

Figure 6. The ratio of $\mathrm{Hg}$ to Te obtained from EDX measurements on electrodeposited HgTe produced with a range of different potentials and equimolar and Te-rich plating baths measured at acceleration voltages of (a) $10 \mathrm{keV}$ and (b) $20 \mathrm{keV}$. The results from a standard bulk sample are presented as a horizontal line for the average and a labelled data point on the far left.

used the Halder-Wagner approach to extract the "crystallite size" for the different HgTe films as shown in Figure 5. The 220 and 311 peaks were excluded from this analysis due to the overlapping Pt peaks. The results of the Halder-Wagner analysis presented in Figure $5 b$ clearly show that the crystallite size is significantly larger for the more positive deposition potentials; in fact they approach the resolution limit of the technique.

Composition of the HgTe deposits.-A series of EDX measurements was performed to quantify the composition of a range of deposited films. In general, the obtained EDX spectra (see Figure S9 in the Supporting Information) showed strong features associated with $\mathrm{Hg}, \mathrm{Te}, \mathrm{Pt}$ and $\mathrm{Si}$ and trace peaks associated with $\mathrm{O}$ and $\mathrm{C}$ at background levels. The $\mathrm{Hg}$ : Te ratio was determined by fitting the $\mathrm{Hg}$ (M-line $2.195 \mathrm{keV}$ ), Te (L-line $3.769 \mathrm{keV})$, Si (K-line $1.739 \mathrm{keV})$ and $\mathrm{Pt}(\mathrm{M}$-line $2.048 \mathrm{keV})$ lines. Before undertaking the main composition measurements, a study was performed to investigate the optimum conditions, i.e. acceleration voltage and film thickness, for the remaining measurements. These measurements were performed on a series of samples deposited from a plating bath containing $5 \times 10^{-3} \mathrm{~mol} \mathrm{dm}^{-3}$ each of $\left[\mathrm{N}^{\mathrm{n}} \mathrm{Bu}_{4}\right]_{2}\left[\mathrm{HgCl}_{4}\right]$ and $\left[\mathrm{N}^{\mathrm{n}} \mathrm{Bu}_{4}\right]_{2}\left[\mathrm{TeCl}_{6}\right]$ in $0.1 \mathrm{~mol} \mathrm{dm}^{-3}\left[\mathrm{~N}^{\mathrm{n}} \mathrm{Bu}_{4}\right] \mathrm{Cl}$ in $\mathrm{CH}_{2} \mathrm{Cl}_{2}$ at $-1.75 \mathrm{~V}$ using deposition times of 3600,1800 and $300 \mathrm{~s}$. The details of this study are presented in the Supplementary Information (Figure S9 to S11). These results showed that in all cases the reported $\mathrm{Hg}$ : Te ratio of the films increased with increasing acceleration voltage from 10 to 20 to $30 \mathrm{keV}$ in an approximately linear manner, that this effect was stronger for thinner samples (lower deposition time), and that at $20 \mathrm{keV}$ the composition was nearly independent of sample thickness/deposition time. Based upon these measurements, all further measurements were performed on samples prepared using a cutoff charge $\left(0.8 \mathrm{C} \mathrm{cm}^{-2}\right.$, corresponding to a nominal deposit thickness of $556 \mathrm{~nm}$ ), rather than a fixed deposition time. Deposition times for samples prepared using this method were at least $600 \mathrm{~s}$ for deposits obtained at $-1.75 \mathrm{~V}$. At least three independent measurements at $10 \mathrm{keV}$ and $20 \mathrm{keV}$ acceleration voltage were performed on each sample to allow the in-sample standard deviation of the composition to be determined. Repeated measurements at a single location showed no evidence of electron beam modification of or damage to the sample. In addition, EDX measurements were performed on melt grown standard bulk $\mathrm{HgTe}$ samples. These were performed on freshly polished surfaces. SE images of the standard samples showed the presence of grains of $\mathrm{HgTe}$ surrounded by grain boundaries rich in
Te. Thus, the results on the standard reported here were taken from the center of the HgTe grains. The $\mathrm{Hg}$ : Te ratio obtained on 25 samples deposited at a range of deposition potentials and with both equimolar $\left(5 \times 10^{-3} \mathrm{~mol} \mathrm{dm}^{-3}\right.$ each $)$ and tellurium rich $\left(4 \times 10^{-3}: 5 \times 10^{-3}\right.$ mol dm${ }^{-3}$ of $\left[\mathrm{N}^{\mathrm{n}} \mathrm{Bu}_{4}\right]_{2}\left[\mathrm{HgCl}_{4}\right]$ and $\left[\mathrm{N}^{\mathrm{n}} \mathrm{Bu}_{4}\right]_{2}\left[\mathrm{TeCl}_{6}\right]$ in $0.1 \mathrm{~mol} \mathrm{dm}^{-3}$ $\left[\mathrm{N}^{\mathrm{n}} \mathrm{Bu}_{4}\right] \mathrm{Cl}$ in $\mathrm{CH}_{2} \mathrm{Cl}_{2}$ ) plating baths are presented in Figure 6 along with the bulk standard sample measurements.

As can be seen in Figure 6 the composition of the electrodeposited $\mathrm{HgTe}$ films measured using EDX is close to stoichiometric (50 at\% $\mathrm{Hg}$ ) in all cases. Whilst subtle, there is some evidence that sample thickness variations may be affecting the measured composition by a few percent; particularly at either end of the deposition potential range. For instance, EDX measured composition for the samples deposited at $-1.75 \mathrm{~V}$ at $10 \mathrm{keV}$ varies more than that at $20 \mathrm{keV}$ and in general the $10 \mathrm{keV}$ measured composition has a lower $\mathrm{Hg}$ content. Both observations can be explained by sample thickness variations using the previously discussed trends in reported composition with sample thickness. At the most positive deposition potentials $(-0.5 \mathrm{~V}$ and $-0.25 \mathrm{~V})$ the reported composition also varies much more significantly with acceleration voltage than in samples deposited in the middle of the deposition potential range with the reported $\mathrm{Hg}$ content lower at $10 \mathrm{keV}$ than $20 \mathrm{keV}$. Bearing this in mind, it is not clear that the variation in the measured compositions is actually a reflection of real compositional differences. It is clear that the variation in measured composition within a single sample is in general greater than the variation between repeats under the same conditions and thus to within the experimental errors of $1-2 \%$ the composition is reproducible. Whilst in the majority of cases the samples deposited from the plating bath containing the lower concentration of the $\mathrm{Hg}$ reagent ( $4 \mathrm{mM}$ ) have lower measured $\mathrm{Hg}$ content, the differences are comparable with the experimental errors and the variation in $\mathrm{Hg}$ content in the samples is small considering the change in the plating bath. Thus, the bulk of the evidence supports the hypothesis that it is possible to deposit stoichiometric HgTe using the plating baths reported here over a wide range of deposition potentials from at least $-1.25 \mathrm{~V}$ to $-0.5 \mathrm{~V}$ and the composition of the deposit is relatively insensitive to the ratio of $\mathrm{Hg}$ to $\mathrm{Te}$ in the electrolyte.

Electrodeposition onto an alternative substrate.-In order to explore whether the HgTe electrodeposition method presented here could be used on a different substrate, depositions were performed on TiN at $-0.8 \mathrm{~V},-1 \mathrm{~V},-1.5 \mathrm{~V}$ and $-1.75 \mathrm{~V}$ from a plating bath 
containing $5 \times 10^{-3} \mathrm{~mol} \mathrm{dm}{ }^{-3}$ each of $\left[\mathrm{N}^{\mathrm{n}} \mathrm{Bu}_{4}\right]_{2}\left[\mathrm{HgCl}_{4}\right]$ and $\left[\mathrm{N}^{\mathrm{n}} \mathrm{Bu}_{4}\right]_{2}\left[\mathrm{TeCl}_{6}\right]$ in $0.1 \mathrm{~mol} \mathrm{dm}{ }^{-3}\left[\mathrm{~N}^{\mathrm{n}} \mathrm{Bu}_{4}\right] \mathrm{Cl}$ in $\mathrm{CH}_{2} \mathrm{Cl}_{2}$. The deposited films were investigated using XRD and EDX (see Supplementary Information, Figures S12 and S13). In all cases the XRD results showed clear evidence for crystalline HgTe and all other peaks could be associated with the sputtered TiN or underlying silicon substrate. The EDX compositions measured at $10 \mathrm{keV}$ ranged from $48 \%$ to $48.9 \% \mathrm{Hg}$ contents. Considering the thinner deposits produced in these experiments these are well within the range of compositions reported for thinner $\mathrm{HgTe}$ films produced on $\mathrm{Pt}$ measured at the same acceleration voltage. Thus, we can conclude that the $\mathrm{HgTe}$ electrodeposition method is also applicable to deposition on TiN.

\section{Conclusions}

In this paper we have set out a robust method for electrodepositing crystalline HgTe using a non-aqueous electrolyte. This method produces crystalline $\mathrm{HgTe}$ on $\mathrm{Pt}$ and $\mathrm{TiN}$ substrates over a wide range of deposition potentials, -0.25 to $-2 \mathrm{~V}$ vs. $\mathrm{Ag} / \mathrm{AgCl}$. The crystallite size can be manipulated using the deposition potential with an average crystallite size of greater than $100 \mathrm{~nm}$ achieved at a deposition potential of $-0.5 \mathrm{~V}$. After a series of studies to determine the optimum method and conditions for composition measurements, the electrodeposited $\mathrm{HgTe}$ has been shown to be stoichiometric over most, if not all, of the deposition potential range by SEM EDX. The composition of the film is relatively insensitive to the electrolyte composition with stoichiometric $\mathrm{HgTe}$ being electrodeposited from plating baths containing either $5 \times 10^{-3} \mathrm{~mol} \mathrm{dm}^{-3}$ each or $4 \times 10^{-3}: 5 \times 10^{-3} \mathrm{~mol} \mathrm{dm}^{-3}$ of $\left[\mathrm{N}^{\mathrm{n}} \mathrm{Bu}_{4}\right]_{2}\left[\mathrm{HgCl}_{4}\right]$ and $\left[\mathrm{N}^{\mathrm{n}} \mathrm{Bu}_{4}\right]_{2}\left[\mathrm{TeCl}_{6}\right]$ in $0.1 \mathrm{~mol} \mathrm{dm}{ }^{-3}\left[\mathrm{~N}^{\mathrm{n}} \mathrm{Bu} 4\right] \mathrm{Cl}$ in $\mathrm{CH}_{2} \mathrm{Cl}_{2}$. The films are not entirely smooth, as expected given their polycrystalline nature. Films of thickness of $1 \mu \mathrm{m}$ can be deposited in approximately $1800 \mathrm{~s}$, depending on the deposition potential. This deposition rate is comparable to that achieved by MBE growth; $3.5 \mu \mathrm{m} / \mathrm{hr}^{25}$

It is interesting to compare this study to the limited previous work on electrodeposition of $\mathrm{HgTe}$, especially as this is the first non-aqueous electrolyte that has been used to electrodeposit crystalline $\mathrm{HgTe}$. The $\mathrm{HgTe}$ produced is at least of comparable quality to that produced from aqueous electrolytes by Stickney and Ortega in terms of stoichiometry and all three electrolytes produce crystalline $\mathrm{HgTe}$. Both Stickney and Ortega report a tendency for excess tellurium to be deposited. In the case of Stickney, the excess tellurium is removed in a stripping step during each of the ECALE cycles. In the case of Ortega, this tendency leads to most deposits being Te rich, presumably due to the films being a mixture of $\mathrm{Te}$ and $\mathrm{HgTe}$, with stoichiometric films only possible with careful deposition potential control. The new electrolyte shows no tendency to deposition of tellurium over a wide potential range despite the fact that tellurium will deposit from a similar electrolyte with the $\mathrm{Hg}$ removed. ${ }^{18}$ It is not possible to compare the crystallinity achieved with the three methods as the necessary data were not reported for the aqueous electrolytes. The $2 \mu \mathrm{m} / \mathrm{hr}$ deposition rate achievable with the method reported here is, as expected, significantly greater than that achievable by ECALE, $\sim 0.1 \mu \mathrm{m} / \mathrm{hr}$.

As stated in the introduction, $\mathrm{HgTe}$ is an interesting material both technologically and scientifically. Whilst other, already well developed, techniques for $\mathrm{HgTe}$ deposition exist, we believe this work shows that electrodeposition of $\mathrm{HgTe}$ could have an exciting niche in the production of HgTe nanowires. We have shown that it is possible to produce stoichiometric, crystalline $\mathrm{HgTe}$ with an average crystallite size of $100 \mathrm{~nm}$. This opens up the possibility to produce single crystal nanowires using a wide range of templates, including anodic alumina and track etch membranes, without the need for etching, which has shown to have detrimental effects on $\mathrm{HgTe}$.

\section{Acknowledgments}

This work has been supported by the EPSRC through the Program grant, Advanced Devices by Electroplating (ADEPT EP/N0354371/1) and the Standard Research Grants, Enabling microfocus \& thin film X-ray scattering at the University of Southampton $(\mathrm{EP} / \mathrm{K} 009877 / 1)$ and University of Southampton - Equipment Account (EP/K00509X/1). P.N.B. gratefully acknowledges receipt of a Wolfson Research Merit Award. The authors thank Dr Josephine Corsi for editorial support. All the data presented in this paper can be freely accessed from the Southampton Data Repository: DOI: 10.5258/SOTON/D0711.

\section{ORCID}

Gabriela P. Kissling (D https://orcid.org/0000-0003-4701-7160 Ruomeng Huang (D) https://orcid.org/0000-0003-1185-635X

Andrew L. Hector (D) https://orcid.org/0000-0002-9964-2163

Gillian Reid (1) https://orcid.org/0000-0001-5349-3468

Cornelis H. de Groot (D) https://orcid.org/0000-0002-3850-7101

Richard Beanland (D) https://orcid.org/0000-0003-1749-4134

Philip N. Bartlett (1D https://orcid.org/0000-0002-7300-6900

\section{References}

1. X. Chen, Y. Wang, T. Cui, Y. Ma, G. Zou, and T. Iitaka, J. Chem. Phys., 128, 194713 (2008).

2. M. König, S. Wiedmann, C. Brüne, A. Roth, H. Buhmann, L. W. Molenkamp, X.-L. Qi, and S.-C. Zhang, Science, 318, 766 (2007).

3. L. Maier, J. B. Oostinga, D. Knott, C. Brüne, P. Virtanen, G. Tkachov, E. M. Hankiewicz, C. Gould, H. Buhmann, and L. W. Molenkamp, Phys. Rev. Lett., 109, 186806 (2012).

4. A. Rogach, S. V. Kershaw, M. Burt, M. T. Harrison, A. Kornowski, A. Eychmüller, and H. Weller, Adv. Mater, 11, 552 (1999).

5. S. Keuleyan, E. Lhuillier, V. Brajuskovic, and P. Guyot-Sionnest, Nat. Photon., 5, 489 (2011)

6. É. O'Connor, A. O'Riordan, H. Doyle, S. Moynihan, A. Cuddihy, and G. Redmond, Appl. Phys. Lett., 86, 201114 (2005).

7. P. Capper and J. Garland, Mercury Cadmium Telluride: Growth, Properties and Applications, John Wiley \& Sons, Ltd., Chichester, UK (2011).

8. D. Lincot, Thin Solid Films, 487, 40 (2005).

9. M. Schlesinger and M. Paunovic, Modern Electroplating, John Wiley \& Sons, Inc., New York, N.Y. (2000)

10. V. Venkatasamy, N. Jayaraju, S. M. Cox, C. Thambidurai, M. Mathe, and J. L. Stickney, J. Electroanal. Chem., 589, 195 (2006).

11. S. Rath and S. N. Sahu, Europhys. Lett., 67, 294 (2004).

12. S. Rath, A. K. Dash, S. N. Sahu, and S. Nozaki, Int. J. Nanosci., 3, 393 (2004).

13. S. Rath, G. B. N. Chainy, S. Nozaki, and S. N. Sahu, Physica E, 30, 182 (2005).

14. J. Ortega, An. Quim., 88, 459 (1992).

15. B. M. Basol and E. S. Tseng, Appl. Phys. Lett., 48, 946 (1986).

16. S. Chauhan and P. Rajaram, Sol. Energy Mater. Sol. Cells, 92, 550 (2008).

17. B. A. Ashenfelter and T. P. Bigioni, Mater. Sci. Semicond. Process., 25, 18 (2014).

18. P. N. Bartlett, D. Cook, C. H. de Groot, A. L. Hector, R. M. Huang, A. Jolleys, G. P. Kissling, W. Levason, S. J. Pearce, and G. Reid, RSC Adv., 3, 15645 (2013).

19. D. M. Adams, J. Chatt, J. M. Davidson, and J. Gerratt, J. Chem. Soc., 2189 (1963)

20. D. B. G. Williams and M. Lawton, J. Org. Chem., 75, 8351 (2010).

21. Inorg. Cryst. Struct. Database (ICSD, Fiz Karlsruhe) accessed via EPSRC-funded Natl. Chem. Database Serv. hosted by R. Soc. Chem.

22. A. I. Danilov, E. B. Molodkina, Y. M. Polukarov, and J. M. Feliu, Russ. J. Electrochem., 38, 754 (2002)

23. H. L. Wu, S. Yau, and M. S. Zei, Electrochim. Acta, 53, 5961 (2008).

24. Y. Liftman, M. Albeck, J. M. E. Goldschmidt, and C. Yarnitsky, Electrochim. Acta, 29, 1673 (1984).

25. S. Dvoretsky, N. Mikhailov, Y. Sidorov, V. Shvets, S. Danilov, B. Wittman, and S. Ganichev, J. Electron. Mater., 39, 918 (2010). 